\title{
Granger Causality Test Analysis Spillover Effects on SFTZ to Ningbo Economic Growth
}

\author{
Guo Yue \\ Management School in Nanjing University \\ Nanjing, P.R. China
}

\author{
Yuan Jiake, Pan Yuqi \\ Economics \& Management School in Ningbo University of \\ Technology \\ Ningbo, P.R. China
}

\author{
Guo Tailai \\ Huizhou Academic School
}

\begin{abstract}
Setting up Shanghai free trade zone (SFTZ) opened a new era opening to the outside, which was also the booster of accelerating China's participation in the world economy. SFTZ have done many institutional innovation, and have brought great influence to the surrounding cities. As the important port city of Yangtze River delta region, Ningbo will be the first to face all kinds of opportunities and challenges. This paper will use Granger Causality Test and verity to analyze the relations between Shanghai and Ningbo, it also will apply overflow relevant economic theory to analyze SFTZ with Ningbo economic spillover effects and radiation effects qualitatively.
\end{abstract}

Keywords-Shanghai Free Trade Zone(SFTZ); Ningbo; Spillover Effects; Economic Growth; Granger Causality Test

\section{INTRODUCTION}

\section{A. The background of SFTZ establishment}

After financial crisis 2008, America pushed out the TransPacific Partnership Agreement (TPP) and the Transatlantic Trade and Investment Partnership (TTIP), whom tried to promote these regulations to replace WTO and become the new rules for global trade. But these regulations were benefited for developed countries' in general and unfavorable to emerging and developing countries. Under the background of global trade competition aggravating, Chinese import and export markets faced more pressure, so that Chinese international trade growth slow down from 2014 till now. And at this time the SFTZ establishment can be a good path to avoid above risk and reduce the competition pressure of global trade. China can get more experiences to enterprise the international business and increase the competitiveness capability for participating in international economic and trade.

At present, China still existed many problems in economic development mode, such like high energy consumption, low efficiency, excess capacity, etc. In recent years, with the rising labor costs, Chinese companies' competitive capability are becoming lower in this area, which means that China can not a long time rely on exports to drive the domestic economy growth. [1] (Chen, 2013) Therefore, at this stage, China urgently needs a scientific economic development model to guide the domestic market, improve Chinese scientific and technological innovation capability, and increase the core competitiveness capability in international trade. China government created SFTZ, the first reason is to learn and draw lessons from advanced experience of developed countries, another reason is to explore new economic growth mode making China can be integrated into the globalization tide better than before.

China's financial markets are relatively closed comparing with open and free commodity markets. Due to lack of good investment opportunities, the investors had to invest in real estate area, it resulted in real estate prices higher. In addition, the efficiency of state-owned banks is getting lower and lower, the fund is used inefficient. Many small and medium enterprises (SMEs) obtain loans only from non-standard financial institutions because of they are difficult to borrow the money from the banks, and the government cannot control the shadow banks very well. SFTZ can be set up to enable its effects, such as foreign financial institutions and insurance companies can set up subsidiaries in SFTZ, and then to domestic investors recommended, someone has been limited financial products in the market, which proved current financial system development more rigid.

From the foreigner point of view, SFTZ's financial system is a signal of openness, you can make Chinese currency, that is, the Yuan more involved into international financial investment, which will accelerate RMB in the global circulation. From the internal perspective, the SFTZ can also attract variety of investment, which making a large number of capital gathered into Shanghai. After that, SFTZ is setting up the RMB capital account using precipitation in overseas RMB investment for a domestic industry development prospects in less risk or can effectively control the risks. Whole these activities can make $\mathrm{RMB}$ has become more and more decisive role in the international economic trade.

\section{B. SFTZ development process}

Establishment SFTZ in 2013 to the Chinese economics reform is great significance. The construction of SFTZ with China's reform and opening to the outside world is related closely, the review of China's reform and opening-up process can be roughly divided into four stages. [2] (Xu, 2015) The first stage is in the late 1970s and the early 1990s, China put forward and in the country began to implement the policy of 
reform and opening to the outside world. During this period, the economic development proposed to open to the outside world.

The second stage is from 1992 to entry into World Trade Organization (WTO), before this stage in the economic development proposed the export-oriented economy, mainly to export leading, China participated into international economic and trade actively. In this period time, China has been actively involved in global economic and trade efforts to integrate into the tide of economic globalization. China finally in 2001 successfully became a WTO member. So far, Chinese market were once again the opening to the world, and Chinese international trade increased and more competitive.

The third stage is from the beginning of 2001 to now, China put forward to establish a safety, efficient open economy that is actually Chinese economic transformation and upgrading. The process, from 2009 began to now, China's government held out a new strategy of reform and opening economic, which will propose deepening coastal, ascend along the edge, the rise of Central China, and the revitalization of the Northeast in this strategic layout.

In recent years, various countries are constantly trying to find the most suitable for their own path to prove the economic growth. Therefore, China has learned the advanced countries' development experiences, established such as the SFTZ and other economic zones to promote economic growth in all parts of the country. In addition, there have also introduced the establishment of many special regional in whole countries, for example, export processing zones, bonded port zone, bonded zone, and opened the highest form of Comprehensive Bonded Zone. At the same time in 2009, China government also approved the Horses International Trade Center. All these are represented such a reform and opening up of the prototype from the coast to the border, from the central to northeast in China.

Unfortunately, there need a good path to achieve the strategic target to get higher results. Therefore, Shanghai built up a more large free trade zone in this environment, which aimed to promote the transformation and upgrading a new economic model to prove Chinese economic development in the further and greater, more innovation in the reform and opening up.

\section{Characteristics of SFTZ}

As the introduction of foreign advanced experience, vigorously promote the first FTA in China, SFTZ would put more economical and policy reform in there, makes the sea and surrounding areas more active docking and linking the world. [3] (Wu and Zhou, 2013) At the same time, it can also make China constantly learn and absorb the experience of foreign trade, and promote the upgrading of Chinese economic development.

Secondly, Chinese economy can be changed from the labor-intensive to knowledge-based and technological innovation by the continuous innovation and innovation capability improvement. In the process of building the SFTZ, the Shanghai government has made great efforts to develop and reform the economic system. Therefore, Chinese government has gained the experience accumulated from regional economic development on the basis of implementing the negative list management model in Shanghai. Finally, SFTZ establishment can play a very good role model, which provides a new strategy thinking for China's open economy, but also provides valuable development experiences for other free trade zone across the country in the future.

\section{METHODOLOGY}

Granger's original definition of non-causality [4] (Granger, 1969) has received so much attention in economics that it scarcely needs any introduction [see e.g. the papers by Detour and Renault [5], Geek et. Al. [6], Lütkepoh 1 [7], Newbold [8], Pierce and Haigh [9], and Sims [10], for surveys, related results, and relevant references]. The Granger causality test is a statistical hypothesis test for determining whether one time series is useful in forecasting another. Granger also stressed that some studies using 'Granger causality' testing in areas outside economics reached 'ridiculous' conclusions

Granger defined the causality relationship based on the following principles:

Given these two assumptions about causality, Granger proposed to test the following hypothesis for identification of a causal effect of $\mathrm{x}$ on $\mathrm{y}$ :

$$
P[Y(t+1) \in A \mid \chi(t)] \neq P\left[Y(t+1) \in A \mid \chi_{-x}(t)\right]
$$

Where $P$ refers to probability, $A$ is an arbitrary non-empty set, and $\chi(t)$ and $\chi_{-x}(t)$ respectively denote the information available as of time $t$ in the entire universe, and that in the modified universe in which $X$ is excluded. If the above hypothesis is accepted, we say that $X$ Granger-causes $Y$. [11], [12] (Granger, 1980; Granger, 2004)

A time series $X$ is said to Granger-causes $Y$ if it can be shown, usually through a series of t-tests and F-tests on lagged values of $X$ (and with lagged values of $Y$ also included), that those $X$ values provide statistically significant information about future values of $Y$.

$$
\begin{aligned}
& y_{i}=\sum_{i=1}^{q} \alpha_{i} x_{t-i}+\sum_{j-1}^{q} \beta_{j} y_{t-j}+u_{1 t} \\
& x_{i}=\sum_{i-1}^{s} \lambda_{i} x_{t-i}+\sum_{j-1}^{s} \delta_{j} y_{t-j}+u_{2 t}
\end{aligned}
$$

In the Granger-sense $x$ is a cause of $y$ if it is useful inforecasting $\mathrm{y} 1$. In this framework 'useful' means that $\mathrm{x}$ is able to increase the accuracy of the prediction of $y$ with respect to a forecast, considering only past values of $y$.

Definition 1: Assuming to have an information set $\Omega_{t}$ with the form $\left(x_{t}, x_{t-1}, y_{t}, \ldots . y_{t-j}\right)$, we say that $x_{t}$ is Granger causal for $y_{t}$ wrt. $\Omega_{t}$ If the variance of the optimal linear predictor of $y_{t+h}$, based on $\Omega_{t}$, has smaller variance than the optimal linear predictor of $y_{t+h}$ based only on lagged values of $y_{t}$, for any $\mathrm{h}$ ? Thus, $\mathrm{x}$ Granger-causes $\mathrm{y}$ if and only 
if $\sigma_{1}^{2}\left(y_{t}: y_{t-j}, x_{t-i}\right)<\sigma_{2}^{2}\left(y_{t}: y_{t-j}\right)$, with $\mathrm{j}$ and $i=1,2,3, \ldots n$ and $\sigma^{2}$ representing the variance of the forecast error.

There are three different types of situation in which $\alpha$ Granger-causality test can be applied:

- In a simple Granger-causality test there are two variables and their lags.

- In a multivariate Granger-causality test more than two variables are included, because it is supposed that more than one variable can influence the results.

- Effect of the main purpose of this paper is to study the SFTZ of Ningbo Economic spillover effect, in view of the validity of the data and the consistency and, select the Ningbo gross domestic product (GDP), as a measure of economic spillover variables.

The empirical results presented in this paper are calculated within a simple Granger-causality test in order to test whether Stock prices 'Granger causes' economic growth and vice versa.

Based on the relevant literature review, this paper selects Shanghai port cargo throughput as explanatory variables. And due to the port for trade in goods can be analyzed from the import and export of the two directions. Therefore, this paper selected a total of three explanatory variables, respectively for the Shanghai port cargo throughput, Shanghai Port domestic cargo throughput, Shanghai foreign trade port cargo throughput (CARTR2), while changes in CARTR2 are measured by the rate of Ningbo GDP growth.

$$
\begin{aligned}
& (G D P)_{t}=\alpha+\sum_{i=1}^{m} \beta_{i}\left(G D P_{1}\right)_{t-i}+\sum_{j=1}^{n} \gamma_{j}\left(C A R T R_{2}\right)_{t-j}+\mu_{t} \\
& \left(\text { CARTR }_{2}\right)_{t}=\theta+\sum_{i=1}^{p} \phi_{i}\left(C A R T R_{2}\right)_{t-i}+\sum_{j=1}^{q} \psi_{j}\left(G D P_{1}\right)_{t-j}+\eta_{t}
\end{aligned}
$$

Based on the estimated OLS coefficients for the equations (5) and (6) four different hypotheses about the relationship between GDP and CARTR2 can be formulated:

- Unidirectional Granger-causality from CARTR2 to GDP. In this case Shanghai foreign trade port cargoes loaded and unloaded increase the prediction of Ningbo economy but not vice versa. We can get:

$$
\sum_{j=1}^{n} \gamma_{j} \neq 0 \text { and } \sum_{j=1}^{q} \psi_{j}=0 .
$$

- Unidirectional Granger-causality from GDP to CARTR. In this case the growth rate of the economy increases the prediction of the Shanghai port cargo throughput but not vice versa. Thus:

$$
\sum_{j=1}^{n} \gamma_{j}=0 \text { and } \sum_{j=1}^{q} \psi_{j} \neq 0 .
$$

- Bidirectional (or feedback) causality. In this case $\sum_{j=1}^{n} \gamma_{j} \neq 0$ and $\sum_{j=1}^{q} \psi_{j} \neq 0$, so in this case the economy growth rate increases the prediction of the Shanghai port cargo throughput.

- Independence between GDP and CARTR. In this case there is no Granger causality in any direction, thus $\sum_{j=1}^{n} \gamma_{j}=0$ and $\sum_{j=1}^{n} \gamma_{j}=0$.

The establishment of the free trade zone, Shanghai will promote the development of Shanghai port and shipping industry, while Ningbo is an important port city where focus on the import and export of goods as adjacent to Shanghai, which will be brought out a certain influence subject to Shanghai port with Ningbo. Hence by obtaining one of these results it seems possible to detect the causality relationship between the Shanghai port cargo throughput, Shanghai Port domestic cargo throughput, Shanghai foreign trade port cargo throughput and the Ningbo economic growth.

From the data of 1985 to 2015 year that was selected as the sample, some of the data are from the statistical yearbook of Shanghai and Ningbo, the relevant data are shown in Table 1:

Because the original data in the table is actually arranged according to the time series. Therefore, here first of all variables are the natural logarithm. Only in this way we can exclude an-isotropic below model construction caused by the influence of, will not change the original time series co integration relationship and short-term adjustment mode, at the same time, the linear data, convenient for model building, after taking the logarithm of the Ningbo city GDP denoted LNY, after taking the logarithm of the Shanghai port cargo throughput, foreign trade throughput and throughput domestic divided into denoted LNG, LNF, LNM. 
TABLEI

THE DATA OF NINGBO GDP AND SHANGHAI PORT CARGO THROUGHPUT

\begin{tabular}{|c|c|c|c|c|}
\hline $\begin{array}{l}\text { particular } \\
\text { year }\end{array}$ & $\begin{array}{c}\text { Ningbo city } \\
\text { GDP }(100 \text { million } \\
\text { yuan })\end{array}$ & $\begin{array}{l}\text { Shanghai port cargo } \\
\text { throughput (10000 tons) }\end{array}$ & $\begin{array}{l}\text { (Shanghai) trade cargo } \\
\text { throughput (million tons) }\end{array}$ & $\begin{array}{c}\text { (Shanghai) foreign trade } \\
\text { cargo throughput (10000 } \\
\text { tons) }\end{array}$ \\
\hline 1985 & 71.05 & 11291 & 8420 & 2871 \\
\hline 1986 & 80.22 & 12604 & 9551 & 3053 \\
\hline 1987 & 95.99 & 12833 & 10152 & 2681 \\
\hline 1988 & 118.62 & 13320 & 10541 & 2779 \\
\hline 1989 & 137.25 & 14604 & 12017 & 2587 \\
\hline 1990 & 141.40 & 13959 & 11366 & 2593 \\
\hline 1991 & 169.97 & 14679 & 11696 & 2983 \\
\hline 1992 & 213.05 & 16297 & 13119 & 3178 \\
\hline 1993 & 315.11 & 17596 & 13344 & 4252 \\
\hline 1994 & 459.66 & 16581 & 12850 & 3731 \\
\hline 1995 & 602.65 & 16567 & 12481 & 4086 \\
\hline 1996 & 784.07 & 16401 & 12265 & 4136 \\
\hline 1997 & 879.10 & 16397 & 11684 & 4713 \\
\hline 1998 & 952.79 & 16387 & 11483 & 4904 \\
\hline 1999 & 1017.08 & 18641 & 12356 & 6285 \\
\hline 2000 & 1144.57 & 20440 & 12807 & 7633 \\
\hline 2001 & 1278.75 & 22099 & 13446 & 8653 \\
\hline 2002 & 1453.34 & 26384 & 15776 & 10609 \\
\hline 2003 & 1749.27 & 31621 & 18653 & 12968 \\
\hline 2004 & 2109.45 & 37897 & 22061 & 15836 \\
\hline 2005 & 2447.32 & 44317 & 25825 & 18492 \\
\hline 2006 & 2874.42 & 53748 & 32480 & 21268 \\
\hline 2007 & 3418.57 & 56144 & 30574 & 25570 \\
\hline 2008 & 3946.52 & 58170 & 30793 & 27377 \\
\hline 2009 & 4329.30 & 59205 & 33394 & 25811 \\
\hline 2010 & 5316.00 & 65339 & 35114 & 30225 \\
\hline 2011 & 6059.24 & 72758 & 38980 & 33778 \\
\hline 2012 & 6582.21 & 73559 & 37734 & 35825 \\
\hline 2013 & 7128.90 & 77575 & 39869 & 37706 \\
\hline 2014 & 7602.50 & 75529 & 38126 & 37403 \\
\hline 2015 & 8011.50 & 71752 & 37228 & 34524 \\
\hline
\end{tabular}

(Sources: Ningbo Statistic Bureau)

\section{EMPIRICAL ANALYSIS}

\section{A. Unit root test}

Unit root test is a common method in econometric, it is used to judge economics stable in the time sequence, which can also avoid the data sequence that may arise in the spurious regression phenomenon well. If the unit root test results show that the sequence in a mean within the scope of the orderly fluctuation, and the mean is not with the change of time and change, then the time series volatility is stable. For the unit root test, here will use ADF unit root stationery test method, above the selected four variables (time series has the natural logarithm) were in the further research. With the help by the Eviews analysis software, the results of the analysis are shown as Table 2 .

The Table 2 shows the first order difference in the dLNY. And ddLNY is to carry out the two order difference, $5 \%$ level said 5\% confidence level, $10 \%$ level said $10 \%$ confidence level

After ADF unit root test and found the original time series LNY, LNG, LNF, LNM is not smooth, but variable of LNF and LNM after the first-order differential of the ADF critical values were less than $5 \%$ and $10 \%$ confidence level value, and 
therefore is smooth. Variable LNY, LNG after the second order difference after it is smooth.

TABLEII ADF TEST RESULTS

\begin{tabular}{|c|c|c|c|c|c|c|}
\hline Variable & $A D F$ & $1 \%$ level & $5 \%$ level & $10 \%$ level & Prob.* & Stability \\
\hline LNY & -2.12749 & -3.71146 & -2.98104 & -2.62991 & 0.2362 & Not smooth \\
\hline dLNy & -2.19345 & -3.67932 & -2.96777 & -2.62999 & 0.2127 & Not smooth \\
\hline ddLNY & -3.12636 & -3.75295 & -2.99806 & -2.63875 & 0.0385 & stable \\
\hline LNG & -0.46742 & -3.67932 & -2.96777 & -2.62299 & 0.8839 & Not smooth \\
\hline dLNG & -2.72246 & -3.67932 & -2.96777 & -2.62299 & 0.0825 & Not smooth \\
\hline ddLNG & -7.0223 & -3.68919 & -2.97815 & -2.62512 & 0 & stable \\
\hline LNF & -2.11044 & -4.29673 & -3.56838 & -3.21838 & 0.5195 & Not smooth \\
\hline dLNF & -4.18312 & -4.30982 & -3.57472 & -3.22173 & 0.0134 & stable \\
\hline LNM & -1.76755 & -4.30982 & -3.57472 & -3.22173 & 0.6942 & Not smooth \\
\hline dLNM & -3.6082 & -4.30982 & -3.57472 & -3.22173 & 0.0466 & stable \\
\hline
\end{tabular}

\section{B. Co-integration analysis}

GDP if above the test of four variables as the relationship between: Ningbo GDP, Shanghai port cargo throughput, Shanghai foreign trade port cargo throughput, Shanghai Port domestic cargo throughput and the four co integration. So that the four variables exist between a kind of relationship, that is a long-term equilibrium relationship. Test variables between the existences of co-integration relationship between two ways: The first is based on the regression residuals E-G two step test method. The second method is based on the regression coefficients, such as the Johansen co integration test. Due to the Ningbo and Shanghai port cargo throughput is the second single whole, so we can use the co-integration test. In this paper, the E-G two step test is used to show whether there is a co-integration relationship between variables. Firstly, the variables LNY and LNG are returned to the regression equation:

$$
\begin{aligned}
& L N Y=-14.3472+2.0780 L N G \\
& T(-9.39)
\end{aligned}
$$

TABLEIII RESIDUAL UNIT ROOT TEST RESULTS

\begin{tabular}{|l|l|l|l|l|l|l|}
\hline Variable & $\begin{array}{c}\text { The value of } \\
\text { ADF }\end{array}$ & 1\% level & 5\% level & 10\% level & prob.* & Stability \\
\hline e1 & -2.47629 & -2.64712 & -1.95291 & -1.61001 & 0.0152 & Stable \\
\hline
\end{tabular}

Analysis shows that the regression equation of the residual is smooth in the Table 3, so between the two variables exist long-run equilibrium relationship, that is, they are co whole. That is to say, the GDP of Ningbo with Shanghai port cargo throughput between exist integration relationship and the longrun equilibrium relationship. Results of regression coefficient 2.0780 shows that Shanghai port cargo throughput increased promoted to Ningbo GDP growth. With the Shanghai port cargo throughput increased every 1\%, Ningbo GDP will correspondingly increase $2.0780 \%$. So Shanghai port cargo throughput increase could promote the Ningbo economic development.

From Table4 showed the Granger causality test above, the probability value as a probability, below the unified ( $p$ value). When the $\mathrm{p}$ value of less than 0.05 , which can say at the $5 \%$ significance level, Granger causality was established; similarly, when the $\mathrm{p}$ value less than 0.1 , which shows in the $10 \%$ significant level, Granger causality was established. Otherwise, Granger causality is not established. 
TABLEIV GRANGER CAUSALITY TEST

\begin{tabular}{|l|l|l|l|l|}
\hline \multicolumn{1}{|c|}{ Null Hypothesis : } & \multicolumn{1}{|c|}{ Obs } & \multicolumn{1}{|c|}{ F-Statistic } & Probability & \multicolumn{1}{c|}{ conclusion } \\
\hline LNG does not Granger Cause LNY & 30 & 0.08655 & 0.7709 & accept \\
\hline LNY does not Granger Cause LNG & 30 & 1.05646 & 0.3131 & accept \\
\hline LNF does not Granger Cause LNY & 30 & 0.05609 & 0.8146 & accept \\
\hline LNY does not Granger Cause LNF & 30 & 5.40306 & 0.0279 & refuse \\
\hline LNM does not Granger Cause LNY & 30 & 0.49564 & 0.4875 & accept \\
\hline LNY does not Granger Cause LNM & 30 & 0.45797 & 0.5043 & accept \\
\hline LNG does not Granger Cause LNY & 25 & 3.20649 & 0.0407 & refuse \\
\hline LNY does not Granger Cause LNG & 25 & 1.13357 & 0.4001 & accept \\
\hline LNF does not Granger Cause LNY & 25 & 1.68973 & 0.2068 & accept \\
\hline LNY does not Granger Cause LNF & 25 & 1.1654 & 0.3853 & accept \\
\hline LNM does not Granger Cause LNY & 25 & 9.09409 & 0.0007 & refuse \\
\hline LNY does not Granger Cause LNM & 25 & 1.31156 & 0.3237 & accept \\
\hline
\end{tabular}

The selected time series in a total of 31 variables, so the above in OBS is 30 , said as the lag phase 1, OBS is 25 said as the lag period of 6 . Therefore, the test results showed that, at lag 1 period, between the variables LNY and LNM and LNG there is no Granger causality, between LNY and LNF exist only one-way Granger reason, for Granger cause the original hypothesis LNY not LNF change, refused to original hypothesis made the possibility of type I error 0.0279 , LNY not LNF changes Granger causes less likely to show that in 5\% significant level you can reject the original hypothesis, that LNY is the cause of the Grainger LNF, but LNF is not the cause of Grainger LNY.

Through the analysis found that the lag phase 6, LNG and LNM are the Granger cause of LNY that means Shanghai port cargo throughput and throughput domestic will promote the Ningbo economic growth.

\section{Summary}

After ADF unit root test and found the original time series of LNY, LNG, LNF and LNM are not smooth, but variable LNF and LNM after the first-order differential of the ADF critical values were less than $5 \%$ and $10 \%$ confidence level value, and therefore is smooth. Variable LNY and LNG after the second order difference after it is smooth.

So we can be obtained there exist a long-term equilibrium relationship between GDP of Ningbo and Shanghai port cargo throughput through the co-integration analysis. The regression coefficient results 2.0780 by the regression equation, every $1 \%$ increase in cargo throughput of Shanghai port which can promote Ningbo GDP increase $2.0780 \%$. That is to say, the Shanghai port cargo throughput with the Ningbo GDP has a positive correlation, i.e. the stationery of Shanghai port cargo throughput plays a promoting role to Ningbo GDP increase.

Granger causality test showed that at lag phase 1, between the variables LNY, LNM and LNG there are no Granger causality. LNY is the Granger cause of LNF, but LNF and LNY are not the Granger cause. In the lag phase 6, LNG and LNM are the Granger cause by LNY, that is, to identify the Shanghai port cargo throughput and its domestic throughput promote the Ningbo's economic growth.

\section{ANALYSIS ON THE SFTZ EFFECTS TO NINGBO ECONOMICS}

As above we use the Granger causality test do quantitative analysis for Shanghai port cargo throughput, foreign trade cargo throughput and the Ningbo GDP from 1985 to 2015. Through empirical analysis it is concluded that the Shanghai port cargo throughput can be promoted to Ningbo's economic growth. And Shanghai port construction will because the FTZ and accelerate progress. Also the Granger causality test shows that Shanghai port cargo throughput and domestic throughput promotes Ningbo's economic growth. This fully shows that the influence of the SFTZ opening up positive impact to Ningbo's economy.

\section{A. SFTZ spillover effects to Ningbo}

SFTZ provides a good platform to promote region and the national economic growth transformation for Yangtze River Delta region and even the whole country. Ningbo is very good to undertake the economic spillover effects and future development by the SFTZ course of the geographical advantage (port city and adjacent to Shanghai).

First, SFTZ inspires Ningbo economy toward more extroverted direction, and accelerate urban upgrading and transformation of the old economic structure. SFTZ provides a very convenient platform to establish the free trade area to the international finance corporation and international enterprises stationed for whole Chinese market, which also makes Chinese enterprises to enter into the international market more efficient and convenient. Ningbo companies can less the cost to participate in international trade and import and export goods more quickly than before. Ningbo companies open a subsidiary in SFTZ can be got more competitiveness capabilities in the international business.

Secondly, SFTZ caused good demonstration effect to Ningbo urban construction, especially in many institutional reform and innovation activities. Such as the management of foreign trade free trade economic system and the adjustment of laws and regulations. All of these can be brought certain reference to Ningbo foreign investment management. SFTZ gave a lot of system innovation of preferential policies to Ningbo economic system, such as provide a financial liberalization to trade facilitation and international operations. Which can make Ningbo's economy more open and development through the studying. 


\section{B. SFTZ radiation effect to Ningbo}

\section{1) Cargo trade}

To record in SFTZ, it lies in promoting the negative list management model and the global model. The foreign investment negative list cited the industry can be entered and opened. In addition, the foreign investors in the SFTZ will reduce time and improve the foreign investment efficiency from the examination and approval system. Ningbo can attract some foreign company to set up branch in Ningbo, Ningbo will be the part of SFTZ, thus simplifying trade procedures and reduce the cost to the international business.

\section{2) Port logistics}

According to empirical analysis SFTZ can be improved the Ningbo international trade increased, namely Shanghai port to Ningbo economy take action with gradually increasing. With the Ningbo economic rapid development, it will promote trade growth from the expansion of the port logistics investment and logistics demand, also it will improve the port logistics link, and ultimately promote the port logistics development.

\section{3) Financial aspects}

SFTZ allows foreign banks and private capital and foreign investment to set up a total of Sino foreign joint venture banks and establish a global fund management center. Ningbo can attract the foreign banks settling the branches in Ningbo which will be promoted and developed its financial system. In addition, Ningbo can learn from SFTZ financial system to do its financial reform and optimize its financial markets.

\section{The challenges to Ningbo}

There brings Ningbo some opportunities with SFTZ in further, at the same time, it also brought enormous challenges. First of all, SFTZ will bring significant impact to cluster the strategic resources from the around cities, such like Ningbo. Shanghai owned the rich financial system and policy resources, and Ningbo is lacking these supporting from the outside. Second, Ningbo is a port city, even though it has a good port resource advantage and international trade bases. But facing SFTZ has a series of preferential policies in foreign trade, foreign capital, foreign exchange, and so on. Which greatly promoted the competitiveness advantage for its international business, all these will be effected Ningbo international business development.

\section{CONCLUSIONS}

The establishment of SFTZ, Shanghai will leading reform in the Yangtze River Delta significantly speed the process (Lee,
2013; Xu, 2015). [13], [2] Ningbo Industrial will promote the transformation and upgrading and development by SFTZ. This paper used Granger causality test to verify the SFTZ with Ningbo has spillover effects, through integration analysis that there is a long-term equilibrium relationship between Ningbo GDP and harbor cargo throughput. Granger causality test shows that the Shanghai port cargo throughput and domestic throughput will promote Ningbo economic growth. Effects of radiation by SFTZ, Ningbo faces the reforms of international business, financial system and policy from the learning, then can be promote Ningbo economic development in the future.

\section{ACKNOWLEDGMENT}

This research was financially supported by the Zhejiang Province Postdoctoral Project Foundation (No.BSH1502022).

\section{REFERENCES}

[1] Chen G. (2013) the thinking of practical significance and the development for the SFTZ establishment [J]. Administrative affairs and financial, (17): pp.12-13.

[2] Diebold, Francis X. (2001). Elements of Forecasting (2nd Ed.)[M]. Cincinnati: South Western Publish. pp. 254.

[3] Detour, J.M. And E. Renault. (1998) Short Run and Long Run Causality in Time Series: Theory [J]. Econometrical, 66: pp.1099-1126.

[4] Geek, J., R., Meese and W. Dent. (1983) Comparing Alternative Tests of Causality in Temporal System [J]. Journal of Econometrics, (21): pp.161-194.

[5] Granger C. J. (1969) Investigating Causal Relationships by Econometrics Models and Cross Spectral Methods [J]. Econometrical, (37): pp. 425-435

[6] Granger, C.J. (1980) Testing for causality: A personal viewpoint [J] Journal of Economic Dynamics and Control, (2): pp.329-352.

[7] Granger, C. J. (2004) Time Series Analysis, Cointegration, and Applications [J]. American Economic Review, 94 (3): pp.421-425.

[8] Lee R.L. (2013) The Yangtze River Delta to undertake the Shanghai Free Trade Zone spillover effect [N]. Economic Daily, 12.13 (011).

[9] Lütkepohl, H. (1991) Introduction to Multiple Time Series Analysis (2nd end) [M]. Berlin: Springer-Verilog. Pp.30-52.

[10] Newbolt P. (1982) Causality testing in economics. In: Anderson OD (end) Time series analysis: theory and practice I. Amsterdam, pp. 701 716.

[11] Pierce, D.A. and L.D. Haigh. (1977) Causality in Temporal Systems Characterization and a Survey [J]. Journal of Econometrics, (5): pp. 265 294.

[12] Sims, C.A. (1972) Money, Income and Causality [J]. The American Economic Review, (62): pp. 540-552.

[13] Wu R.R., Zhou H.M. (2013) Construction of China (Shanghai) free trade zone and coordinated development of the Yangtze River Delta [N]. Wuxi Daily, 10.24 (007). 